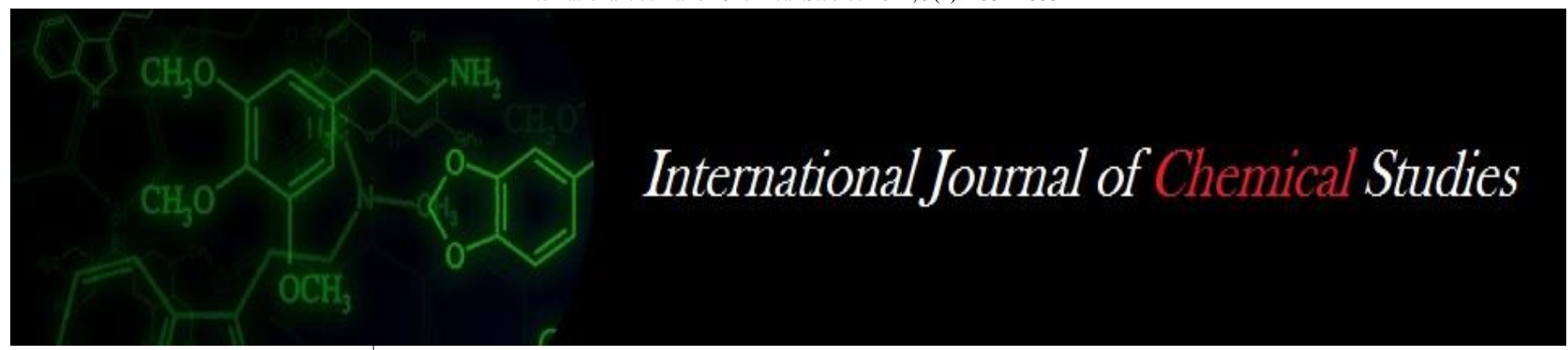

P-ISSN: 2349-8528

E-ISSN: 2321-4902

www.chemijournal.com

IJCS 2021; 9(1): 2884-2888

(C) 2021 IJCS

Received: 14-10-2020

Accepted: 30-12-2020

Morajdhwaj Singh

Department of Plant Pathology,

Sardar Vallabhbhai Patel

University of Agriculture \&

Technology, Modipuram Meerut,

Uttar Pradesh, India

\section{Ramji Singh}

Department of Plant Pathology,

Sardar Vallabhbhai Patel

University of Agriculture \&

Technology, Modipuram Meerut,

Uttar Pradesh, India

\section{Prashant Mishra}

Department of Plant Pathology, Sardar Vallabhbhai Patel

University of Agriculture \&

Technology, Modipuram Meerut,

Uttar Pradesh, India

RS Sengar

Department of Agriculture

Biotechnology, Sardar

Vallabhbhai Patel University of

Agriculture \& Technology,

Modipuram Meerut, Uttar

Pradesh, India

\section{UP Shahi}

Department of Soil Science,

Sardar Vallabhbhai Patel

University of Agriculture \&

Technology, Modipuram Meerut,

Uttar Pradesh, India
Corresponding Author: Morajdhwaj Singh Department of Plant Pathology,

Sardar Vallabhbhai Patel

University of Agriculture \&

Technology, Modipuram Meerut

Uttar Pradesh, India

\section{In-vitro compatibility of Trichoderma harzianum with systemic fungicides}

\author{
Morajdhwaj Singh, Ramji Singh, Prashant Mishra, RS Sengar and UP \\ Shahi
}

DOI: https://doi.org/10.22271/chemi.2021.v9.i1an.11670

\begin{abstract}
Trichoderma spp. are also known as effective bio-control agents against soil-borne pathogens of several important crops. Integration of chemicals and bio-control agents has been the subject of research during recent years. The potential value of bio-pesticides for the control of important plant pathogens requires investigation due to the general requirement for very low pesticides residues in foodstuffs and concerns over the increasing development of resistance to the different classes of chemicals. The aim of the present study was to check the compatibility of different fungicides viz., Hexaconazole, Nativo (Tebuconazole 50\%+ Trifloxystobin 25\%), Propiconazole and Tebuconazole were tested with their different doses of 10, 15, 20 and $25 \mathrm{ppm}$ in vitro for their compatibility with T. harzianum strain IRRI-1 using poisoned food technique. all the four concentrations of Nativo were highly compatible with low toxic effect against T. harzianum strain IRRI-1 in vitro. As there was 74.42, 79.07, 93.02 and 95.35 percent inhibition of radial growth of T. harzianum strain IRRI-1 due to Nativo at 10ppm, 15ppm, 20ppm and $25 \mathrm{ppm}$ concentrations respectively, even after a prolong exposure i.e. up to 96 hours (4 days). 15 and $20 \mathrm{ppm}$ concentration of Propiconazole was completely inhibitory up to 48 hours but after 72 hours, a little growth of T. harzianum strain IRRI-1was visible. $25 \mathrm{ppm}$ concentration of Propiconazole was completely inhibitory up to 96 hours was noticed that the systemic fungicide i.e. Nativo and Propiconazole were comparatively safer, than Hexaconazole and Tebuconazole which exhibited acute toxicity for growth of T. harzianum strain IRRI-1.
\end{abstract}

Keywords: Trichoderma harzianum, fungicides, radial growth, percent inhibition

\section{Introduction}

Different biological control agents (BCAs) can be used for the control of plant diseases. These include fungi, bacteria and actinomycetes. The most important BCAs belong to the genus Trichoderma species, Bacillus species, Pseudomonas species and streptomycetes. Biological control of plant pathogens is an eye-catching alternative to decrease heavy dependence of modern agriculture on costly chemical fungicides, which not only cause environmental pollution but also lead to the development of resistant strains (Harman et al. 2004) ${ }^{[4]}$. To develop an effective disease management programme, the compatibility of potential bio agents with fungicides is essential. Combinations of fungicides and compatible bio agents in an IDM strategy protects the seeds and seedlings from soil borne and seed borne inoculum (Dubey and Patil 2001) ${ }^{[2]}$. Integration of compatible bio agents with fungicides may enhance the effectiveness of disease control and provide better management of soil borne diseases (Papavizas and Lewis 1981) ${ }^{[8]}$. The combination of BCAs with fungicides would provide similar disease suppression as achieved with higher fungicide use (Monte 2001) ${ }^{[2]}$. Combining antagonists with synthetic chemicals eliminates the chance of resistance development and reduces the fungicide application. It is therefore, proposed to identify the compatibility of the potential bio agents with commonly used fungicides for the eco-friendly management of the plant diseases. As fungicides should have inhibitory effect on the pathogen but should not have deleterious effect on the antagonists, an understanding of the effect of fungicides on the pathogen and the antagonists would provide information for the selection of fungicides and fungicide resistant antagonists, through compatibility studies in vitro. In addition, this strategy may display even better control of resistant strains of fungal pathogens and may help the commercial growers to reduce the amount of fungicide use, thus lowering the amount of 
chemical residue in the marketed products. Combined applications of BCAs followed by small quantities of fungicides may help the antagonists and the relative cost of the formulations (Thoudam and Dutta, 2014) ${ }^{[11]}$. It has been reported that many Trichoderma species has an innate and/or induced resistance to many fungicides but the level of resistance varies with the fungicide (Omar, 2006) ${ }^{[7]}$. The combined use of BCAs and chemical pesticides has attracted much attention in order to obtain synergistic or additive effects in the control of soil borne diseases (Locke et al., 1985) ${ }^{[5]}$.

In view of this, investigation was conducted to test the possibility of combining Trichoderma species with fungicides under laboratory condition. The long term goal is to develop an effective IDM package for managing soil borne plant disease as well as to prevent the resistance development in pathogens to fungicides. Integrating chemical resistant Trichoderma species has an importance in the framework of integrated disease management. Disease prevention can be increased by using such tolerant species that keeps pathogens under sufficient pressure so that they cannot thrive. Keeping the above in view, the present work was designed to observe the in vitro compatibility of different fungicides with $T$. harzianum strain IRRI-1.

\section{Methods and Materials}

The experiment was conducted during 2017-18 at the Biocontrol laboratory in the Department of Plant Pathology, College of Agriculture, Sardar Vallabhbhai Patel University of Agriculture and Technology, Meerut (U.P.) India.

A previously characterized drought tolerant isolates of $T$. harzianum strain IRRI-1was selected on the basis of their cultural characteristics and allotted a specific number from Bio-control laboratory. The isolates of $T$. harzianum strain IRRI-1 was maintained on PDA slants and was time to time sub-cultured for its revival. T. harzianum strain IRRI-1 cultured main tend on PDA slants were stored in refrigerator for future use.

\subsection{Preparation of PDA Media}

$250 \mathrm{~g}$ of potato was peeled and cut into small and fine sliced pieces. $200 \mathrm{~g}$ of potato pieces were weighed and placed into a stainless steel pan. $1000 \mathrm{ml}$ of water was added to potato pieces and boiled gently for such a period until they are easily mashed by a glass rod. The decoction thus obtained was filtered through muslin cloth and squeezed out all the liquid in a measuring cylinder and potato pieces were discarded. Now sufficient amount of water was added to make the volume $1000 \mathrm{ml}$. Now pre-weighed $20 \mathrm{~g}$ agar-agar was added $(20 \mathrm{~g})$ slowly to the boiling solution so as to dissolve it. At the same time dextrose $(20 \mathrm{~g})$ was also added in boiling solution (melted with agar) and final volume made up to 1 litre while boiling the solution was stored with glass rod to mix the agaragar and dextrose properly. It was poured @ about $200 \mathrm{ml}$ in each of four conical flasks of $500 \mathrm{ml}$ capacity and $10 \mathrm{ml}$ per culture tube to prepare the PDA slants. Flasks and culture tubes both were tightly plugged with non-absorbent cotton and wrapped with butter paper and rubber bands. The culture tubes and flasks were placed vertically (mouths up) in wire baskets and then autoclaved at $1.1 \mathrm{~kg} / \mathrm{cm}^{2}$ pressure for 20 min at $121.6^{\circ} \mathrm{C}$ and cooled before pouring into Petri plates.

Four fungicides were tested with their different doses of 10 , 15, 20 and 25ppm, in vitro for their compatibility with $T$. harzianum strain IRRI-1 using poisoned food technique. Required amount of fungicides were added in each $250 \mathrm{ml}$ capacity flask, containing $100, \mathrm{ml}$ sterilized PDA media to obtain 10ppm, 15ppm, 20ppm, and 25ppm concentration of each test fungitoxicant. It was mixed thoroughly by shaking the flask prior to pouring in sterilized Petri Plates. The medium was allowed to solidify over night and then $5 \mathrm{~mm}$ discs from seven days old actively growing culture of $T$. harzianum strain IRRI-1 was placed in center of each Petri Plate. PDA medium mixed with distilled water only served as check. Three replications were maintained for each treatment and inoculated plates were incubated at $28 \pm 2{ }^{\circ} \mathrm{C}$ in BOD incubator. Observations were recorded on radial growth of $T$. harzianum strain IRRI-1 at an interval of each $24 \mathrm{hrs}$, up to 5 days. Percent inhibition was calculated by using the formula given below and analyzed under complete randomized design (CRD) (Gomez and Gomez, 1984) ${ }^{[3]}$.

Percent inhibition $=\frac{(\mathrm{C}-\mathrm{T}) \times 100}{\mathrm{C}}$

\section{Where}

$\mathrm{C}=$ Growth of fungus in control

$\mathrm{T}=$ Growth of fungus in treatments

\section{Results and Discussion} 3.1 Results

In total four fungicides viz. Hexaconazole, Nativo (Tebuconazole 50\%+ Trifloxystobin25\%), Propiconazole and Tebuconazole at four concentration viz. 0ppm, 15ppm, 20ppm, and 25ppm were tested for their compatibility with $T$. harzianum strain IRRI-1 in vitro and the data recorded have been presented in Table 1 and Table 2. After thorough review of data table, it is evident that all the four concentrations of Nativo were highly compatible with low toxic effect against T. harzianum strain IRRI-1 in vitro. As there was 74.42, 79.07, 93.02 and 95.35 percent inhibition of radial growth of T. harzianum strain IRRI-1 due to Nativo (Tebuconazole $50 \%+$ Trifloxystobin 25\%) at 10ppm, 15ppm, 20ppm and $25 \mathrm{ppm}$ concentrations respectively, even after a prolong exposure i.e. up to 96 hours (4 days).

Propiconazole was quite toxic to T. harzianum strain IRRI-1 but next in the order of compatibility after Nativo (Tebuconazole 50\%+ Trifloxystobin 25\%). In the initial period of incubation i.e. 48 hours, there was almost complete inhibition at 15, 20, and $25 \mathrm{ppm}$ but as days of incubation increased it seems that toxic effect of chemical get decreased and fungal growth was visualized at $10 \mathrm{ppm}$ concentration of Propiconazole, at a period of 48 hours. Similarly 15 and 20 ppm concentration of Propiconazole was completely inhibitory up to 48 hours but after 72 hours, a little growth of T. harzianum was visible. $25 \mathrm{ppm}$ concentration of Propiconazole was completely inhibitory up to 96 hours.

In the initial period of incubation i.e. at 24 and 48 hours all the concentrations of Hexaconazole were 100 per cent inhibitory of radial growth. However at 72 hours also 15, 20 and $25 \mathrm{ppm}$ concentration of Hexaconazole was completely inhibitory but 10 ppm concentration resulted in 91.18 per cent inhibition. With prolonging incubation period of 96 hours it seems that level of toxicity get reduced and resulted in 88.37, 90.70, 93.02 and 95.35 per cent inhibition due to 10, 15, 20 and 25 ppm concentration of Hexaconazole.

In the initial period of incubation i.e. at 24 hours all the concentrations of Tebuconazole were 100 per cent inhibitory to radial growth. However at 48 and 72 hours also 15, 20 and $25 \mathrm{ppm}$ concentrations were completely inhibitory but $10 \mathrm{ppm}$ concentration resulted in 92.30 and 91.18 percent inhibition. With prolonging incubation period of 96 hours, it seem that 
level of toxicity get little reduced and resulted in 81.40, 90.70, and 95.35 per cent inhibition due to 10,15 and $20 \mathrm{ppm}$ concentrations but $25 \mathrm{ppm}$ concentration was completely inhibitory to radial growth at $96 \mathrm{hrs}$ also.

Overall, it was noticed that the systemic fungicide i.e. Nativo (Tebuconazole50\%+ Trifloxystobin25\%) and Propiconazole were comparatively safer, than Hexaconazole and Tebuconazole which exhibited acute toxicity for growth of $T$. harzianum strain IRRI-1. Compatibility of these chemicals couldn't be assessed beyond 96 hrs because the Petri Plate main tend without any fungi toxicant exhibited 100 percent growth within 96 hrs only.

Table 1: Effect of different concentrations of fungicides on radial growth of Trichoderma harzianum strain IRRI-1 at 24, 48, 72 and $96 \mathrm{~h}$ of their inoculation

\begin{tabular}{|c|c|c|c|c|c|c|}
\hline S. No. & Fungicide/ Treatments & Concentrations & $\begin{array}{c}\text { Radial growth } \\
(\mathrm{mm}) 24 \mathrm{~h}\end{array}$ & $\begin{array}{l}\text { Radial growth } \\
(\mathrm{mm}) 48 \mathrm{~h}\end{array}$ & $\begin{array}{c}\text { Radial growth } \\
(\mathrm{mm}) 72 \mathrm{~h}\end{array}$ & $\begin{array}{l}\text { Radial growth } \\
(\mathrm{mm}) 96 \mathrm{~h}\end{array}$ \\
\hline 1. & \multirow{4}{*}{ Hexaconazole } & $10 \mathrm{ppm}$ & 0.00 & 0.00 & 6.00 & 10.00 \\
\hline 2. & & $15 \mathrm{ppm}$ & 0.00 & 0.00 & 0.00 & 8.00 \\
\hline 3. & & $20 \mathrm{ppm}$ & 0.00 & 0.00 & 0.00 & 6.00 \\
\hline 4. & & $25 \mathrm{ppm}$ & 0.00 & 0.00 & 0.00 & 4.00 \\
\hline 5. & \multirow{4}{*}{$\begin{array}{c}\text { Nativo (Tebuconazole and } \\
\text { Trifloxystrobin) }\end{array}$} & $10 \mathrm{ppm}$ & 0.00 & 8.00 & 12.00 & 22.00 \\
\hline 6. & & $15 \mathrm{ppm}$ & 0.00 & 6.00 & 10.00 & 18.00 \\
\hline 7. & & $20 \mathrm{ppm}$ & 0.00 & 0.00 & 0.00 & 6.00 \\
\hline 8. & & $25 \mathrm{ppm}$ & 0.00 & 0.00 & 0.00 & 4.00 \\
\hline 9. & \multirow{4}{*}{ Propiconazole } & $10 \mathrm{ppm}$ & 0.00 & 4.00 & 10.00 & 16.00 \\
\hline 10 & & $15 \mathrm{ppm}$ & 0.00 & 0.00 & 8.00 & 12.00 \\
\hline 11. & & $20 \mathrm{ppm}$ & 0.00 & 0.00 & 4.00 & 10.00 \\
\hline 12. & & $25 \mathrm{ppm}$ & 0.00 & 0.00 & 0.00 & 0.00 \\
\hline 13. & \multirow{4}{*}{ Tebuconazole } & $10 \mathrm{ppm}$ & 0.00 & 4.00 & 6.00 & 16.00 \\
\hline 14. & & $15 \mathrm{ppm}$ & 0.00 & 0.00 & 0.00 & 8.00 \\
\hline 15. & & $20 \mathrm{ppm}$ & 0.00 & 0.00 & 0.00 & 4.00 \\
\hline 16. & & $25 \mathrm{ppm}$ & 0.00 & 0.00 & 0.00 & 0.00 \\
\hline 17. & Control & - & 30.00 & 52.00 & 68.00 & 86.00 \\
\hline \multicolumn{3}{|c|}{$\mathrm{SE}(\mathrm{m})$} & 0.252 & 0.444 & 0.597 & 0.804 \\
\hline \multicolumn{3}{|c|}{ C.D. } & 0.728 & 1.282 & 1.724 & 2.32 \\
\hline
\end{tabular}

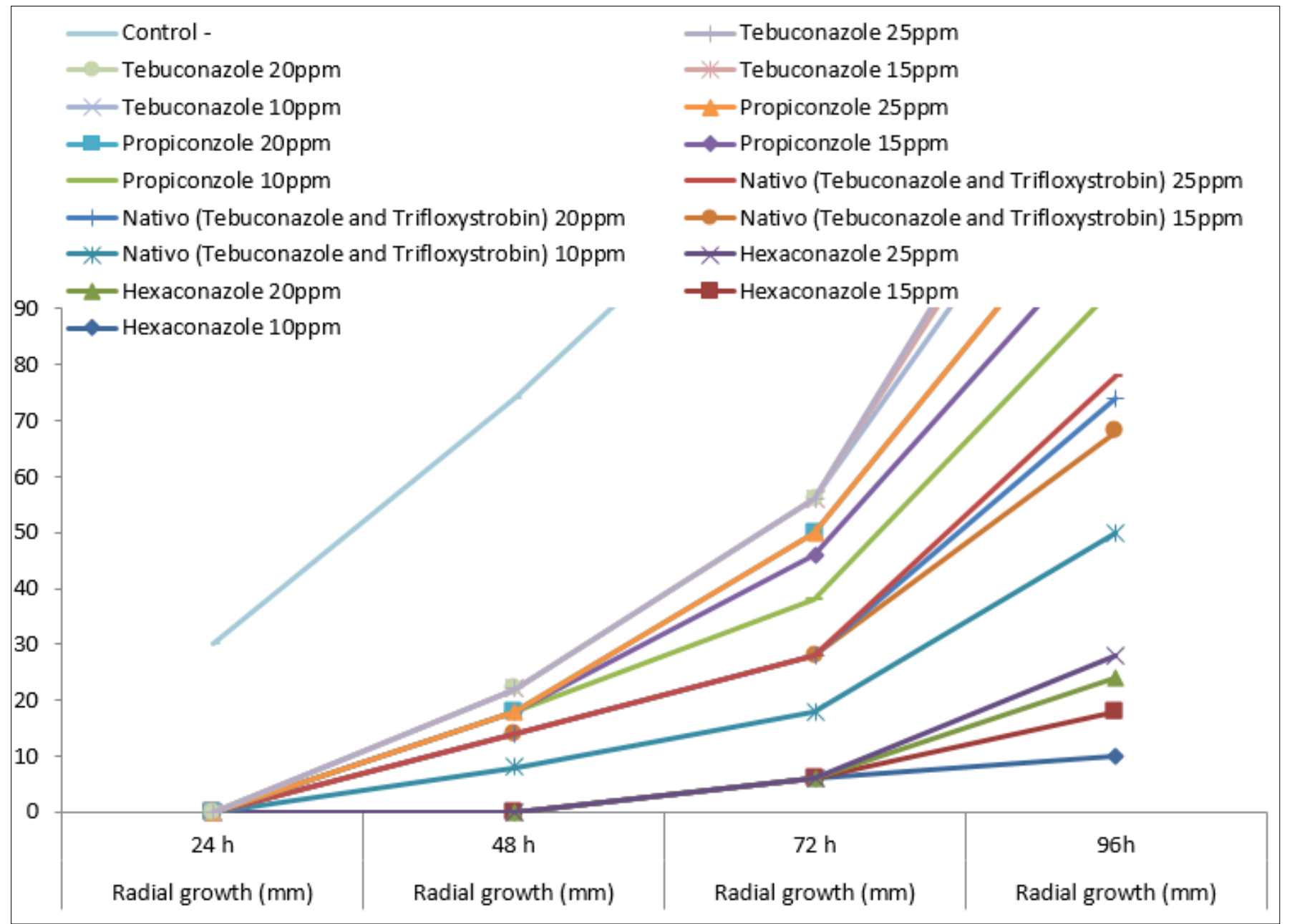

Fig 1: Effect of different concentrations of fungicides on radial growth of Trichoderma harzianum strain IRRI-1 at 24, 48, 72 and $96 \mathrm{~h}$ of their inoculation 
Table 2: Effect of different concentrations of fungicides on percent inhibition of Trichoderma harzianum strain IRRI-1 at 24, 48, 72 and $96 \mathrm{~h}$ of their inoculation

\begin{tabular}{|c|c|c|c|c|c|c|}
\hline & & & Percent Inhibition & Percent Inhibition & Percent Inhibition & Percent Inhibition \\
\hline S. No. & Fungicide/ Treatments & Concentrations & at $24 \mathrm{~h}$ & at $48 \mathrm{~h}$ & at $72 \mathrm{~h}$ & at $96 \mathrm{~h}$ \\
\hline 1. & \multirow{4}{*}{ Hexaconazole } & $10 \mathrm{ppm}$ & 100.00 & 100.00 & 91.18 & 88.37 \\
\hline 2. & & $15 \mathrm{ppm}$ & 100.00 & 100.00 & 100.00 & 90.70 \\
\hline 3. & & $20 \mathrm{ppm}$ & 100.00 & 100.00 & 100.00 & 93.02 \\
\hline 4. & & $25 \mathrm{ppm}$ & 100.00 & 100.00 & 100.00 & 95.35 \\
\hline 5. & \multirow{4}{*}{$\begin{array}{c}\text { Nativo (Tebuconazole and } \\
\text { Trifloxystrobin) }\end{array}$} & $10 \mathrm{ppm}$ & 100.00 & 84.61 & 82.35 & 74.42 \\
\hline 6. & & $15 \mathrm{ppm}$ & 100.00 & 88.46 & 85.29 & 79.07 \\
\hline 7. & & $20 \mathrm{ppm}$ & 100.00 & 100.00 & 100.00 & 93.02 \\
\hline 8. & & $25 \mathrm{ppm}$ & 100.00 & 100.00 & 100.00 & 95.35 \\
\hline 9. & \multirow{4}{*}{ Propiconazole } & $10 \mathrm{ppm}$ & 100.00 & 92.30 & 85.29 & 81.40 \\
\hline 10 & & $15 \mathrm{ppm}$ & 100.00 & 100.00 & 88.24 & 86.05 \\
\hline 11. & & $20 \mathrm{ppm}$ & 100.00 & 100.00 & 94.12 & 88.37 \\
\hline 12. & & $25 \mathrm{ppm}$ & 100.00 & 100.00 & 100.00 & 100.00 \\
\hline 13. & \multirow{4}{*}{ Tebuconazole } & $10 \mathrm{ppm}$ & 100.00 & 92.30 & 91.18 & 81.40 \\
\hline 14. & & $15 \mathrm{ppm}$ & 100.00 & 100.00 & 100.00 & 90.70 \\
\hline 15. & & $20 \mathrm{ppm}$ & 100.00 & 100.00 & 100.00 & 95.35 \\
\hline 16. & & $25 \mathrm{ppm}$ & 100.00 & 100.00 & 100.00 & 100.00 \\
\hline 17. & Control & - & 0.00 & 0.00 & 0.00 & 0.00 \\
\hline
\end{tabular}

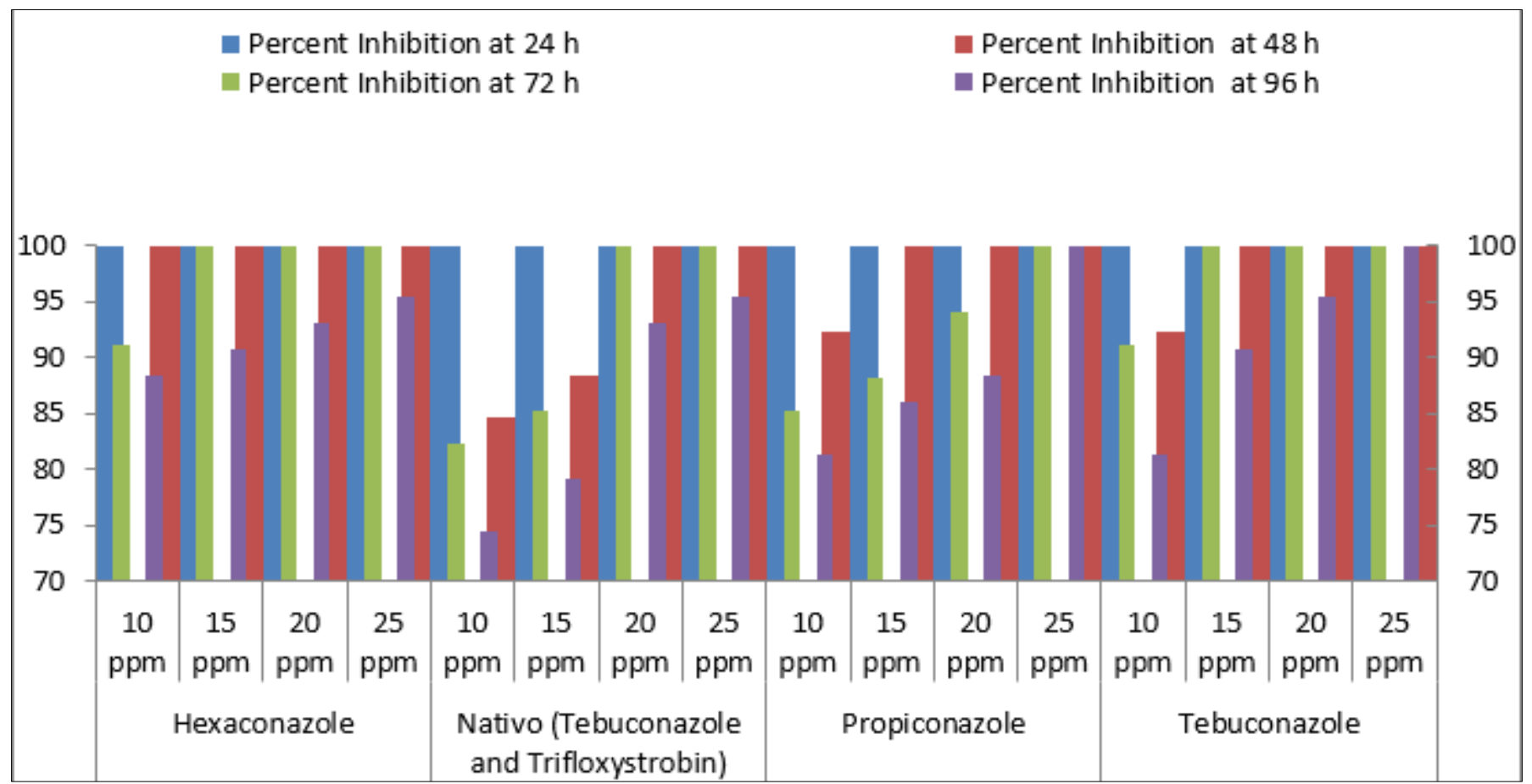

Fig 2: Effect of different concentrations of fungicides on percent inhibition of Trichoderma harzianum strain IRRI-1 at $24,48,72$ and 96 h of their inoculation

\section{Discussion}

It was found that the two systemic fungicides i.e. Hexaconazole and Tebuconazole during the course of investigation were found to be comparatively more toxic and incompatible at any concentration tested against $T$. harzianum strain IRRI-1 than the other two systemic fungicides i.e. Nativo (Tebuconazole 50\%+ Trifloxystobin25\%) and Propiconazole. However, Tebuconazole was comparatively more toxic than Hexaconazole, to T. harzianum strain IRRI-1 at all concentration tested.

Overall, it was noticed that the two fungicides i.e. Nativo and Propiconazole were safer, as compared to Hexaconazole and Tebuconazole which acute toxicity for growth of $T$. harzianum strain IRRI-1.

The literatures suggest that bio control agents that can tolerate a certain level of fungicides were mixed with agrochemicals, resulting in eradication of diseases (De Cal et al., 1994). The results are also in agreement with the works of Mukhopadyay et al., (1987) ${ }^{[6]}$ Sharma and Mishra, (1995) ${ }^{[10]}$ who also found good growth of Trichoderma isolates at low and medium concentrations of various fungicides. Among fungicides, Captan, Thiram, Chlorothalonil and Copper hydroxide were found compatible with the test antagonist up to $100 \mu \mathrm{g}$ a.i. $/ \mathrm{ml}$, while Mancozeb up to $250 \mu \mathrm{g}$ a.i. $/ \mathrm{ml}$, as these did not adversely affect the growth of test antagonist. However, Benomyl, Thiophanate methyl, Bayleton and Ipridione were found incompatible with the test antagonist even at $25 \mu \mathrm{g}$ a.i. $/ \mathrm{ml}$ (Saxena et al., 2014) ${ }^{[9]}$. Present findings indicated that revealed that seed treatment or soil application of Trichoderma could be exploited along with compatible fungicides at their lower concentrations under bio-intensive integrated disease management practices. 


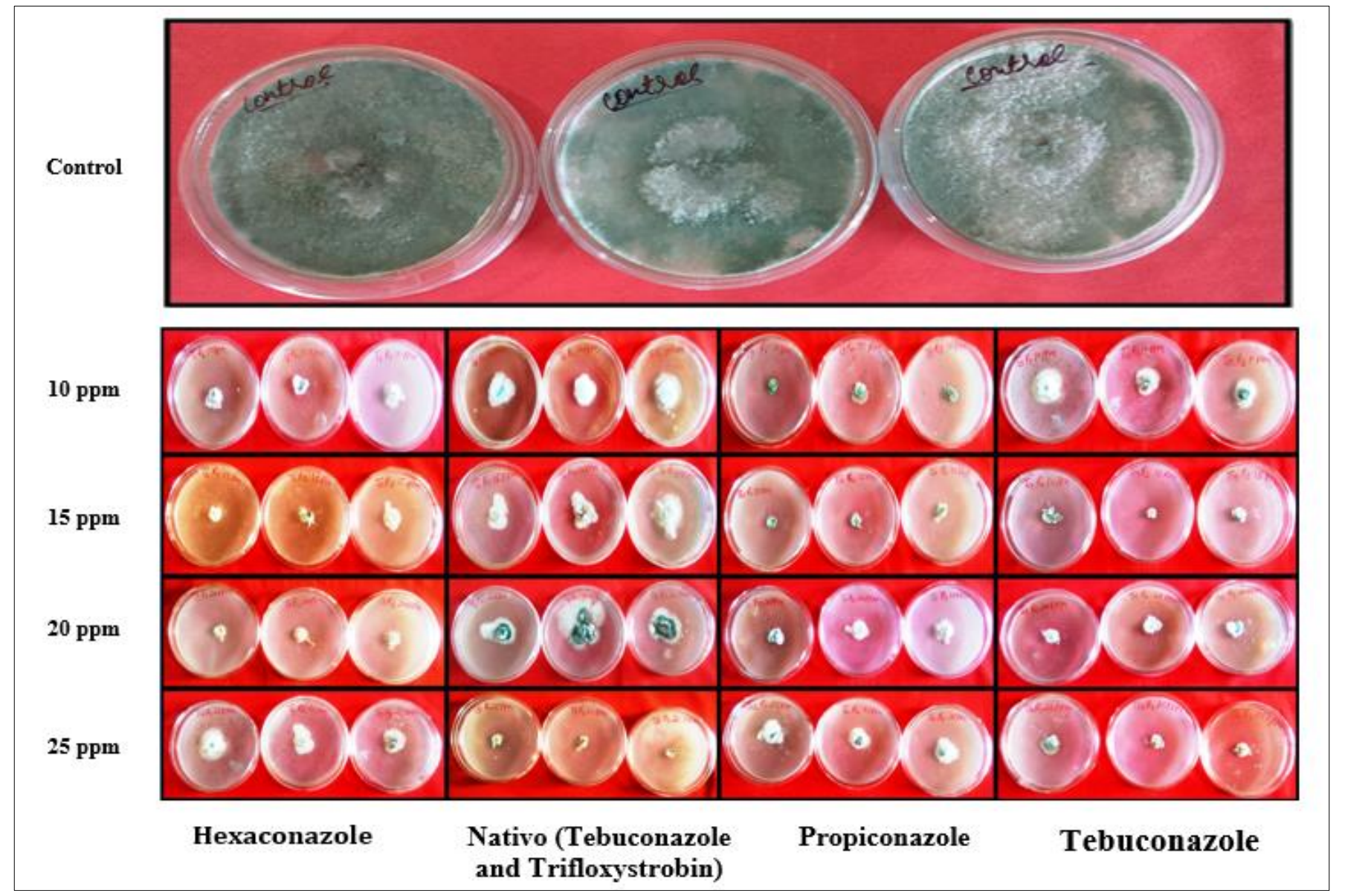

Fig 3: Percent inhibition of Trichoderma harzianum over control in presence of different concentrations of systemic fungicides

\section{Conclusion}

As BCAs cannot handle the disease entirely when bulky size infection is already recognized in the field, farmers prefer fungicides for managing the crop diseases. But fungicides are harmful to the environment and also injurious for the soil, efficiency and human and animal health. Due to the disadvantages of fungicides, IDM programs (100 and 200 ppm for both fungicides) with BCAs are recommended, in which judicious use of fungicides and their integration with BCAs is favored. As fungicides may have harmful effect on antagonists, an indebted of the effect of fungicides on antagonists would provide information on the selection of selective fungicides and fungicides resistant antagonists for compatibility studies as has been suggested in the present paper.

\section{References}

1. De Cal A, Pascual S, Melgarejo P. In vitro studies on the effects of fungicides on beneficial fungi of peach twig mycoflora. Mycopathologia 1994;126:15-20.

2. Dubey SC, Patil B. Determination of tolerance in Thanetophorus cucumeris, Trichoderma viride, Gliocladium virens and Rhizobium sp. to fungicides. Indian Phytopathol 2001;54:98-101.

3. Gomez KA, Gomez AA. Statistical procedures for agricultural research (2 ed.). John wiley and sons, New York 1984, 680.

4. Harman GE, Howell CR, Viterbo A, Chet I, Lorito M. Trichoderma species- opportunistic, avirulent plant symbionts. Nat Rev Microbiol 2004;2:43-56.

5. Locke JC, Maroisand JJ, Papavizas GC. Biological control of Fusarium wilt of greenhouse-grown Chrysanthemums. Plant Dis 1985;69:167-169.
6. Mukhopadyay AN. Biological control of soil borne plant pathogens by Trichoderma spp. Presidential address delivered at the 9th Annual meeting of the Society of Mycology and Plant Pathology. Indian J Mycol. and Plant Pathol 1987;17:1-10.

7. Omar P. Eng. Agricultural use of Trichoderma. Technical revision by Gonzalo Bernaza, Eng and Miguel Acosta, Grad 2006.

8. Papavizas GC, Lewis JA. Introduction and Augmentation of Microbial Antagonists for the Control of Soil-Borne Plant Pathogens. In: Biological Control in Crop Production, Papavizas, G.C. (Ed.). Allanheld and Qsmun, Totowa, New Jersey 1981, 305-322.

9. Saxena D, Tewari AK, Dinesh Rai. The in vitro Effect of Some Commonly Used Fungicides, Insecticides and Herbicides for Their Compatibility with Trichoderma harzianum PBT23, World Appl. Sci. J 2014;31(4):444448.

10. Sharma SD, Mishra A. Tolerance of Trichoderma harzianum to agrochemicals, In: Abst. Global conference on Advances in Research on Plant Diseases and Their Management. February 12- 17, 1995. Rajasthan College of Agriculture, India 1995, 162.

11. Thoudam R, Dutta BK. Compatibility of Trichoderma atroviride with fungicides against black rot disease of tea: an in vitro study. J Int. Academic Research for Multidisciplinary 2014;2:25-33.

12. Wedajo B. Compatibility Studies of Fungicides with Combination of Trichoderma Species under In vitro Conditions. Virol-mycol 2015;4:149. 